\title{
Rupture-Disk Ampoule for Anhydrous Addition of Hydrogen Fluoride*
}

\author{
Augustus R. Glasgow, Jr. ${ }^{1}$ \\ Institute for Materials Research, National Bureau of Standards, Washington, D.C.
}

(January 3, 1966)

\begin{abstract}
The rapid increase in vapor pressure of liquid $\mathrm{HF}$ with temperature has been used in a rupturedisk-ampoule technique for mixing $\mathrm{HF}$ with materials under anhydrous conditions. At room temperature where $\mathrm{HF}$ has a vp near $1.4 \mathrm{~atm}$, the disk with a rupture limit near $10 \mathrm{~atm}$ confines the acid. At higher temperatures, 100 and $150{ }^{\circ} \mathrm{C}$, where the internal pressure of $\mathrm{HF}$ in the ampoule is 10 and 30 atm, respectively, the disk is ruptured and the acid is released. The construction of the ampoule from platinum and reuseable platinum-iridium parts; the details of the filling, sealing and weighing; and its use for anhydrous addition of HF to other materials in a closed vessel are described.
\end{abstract}

Key Words: Anhydrous filling, anhydrous mixing, ampoule, capsule, hydrogen fluoride, metal, rupture-disk.

\section{Introduction}

Glass ampoules with break-tips or thin walls have long been used for the two-fold purpose: one, sealing a volatile substance under its own vapor pressure for weighing, storage, protection of its purity, etc.; and two, providing for the transfer of the substance in the absence of air or moisture to other vessels and to other materials by breaking the tip or thin wall of the ampoule under controlled conditions. A metal, rupturedisk ampoule of platinum and platinum-iridium parts was designed to extend this technique to hydrogen fluoride, whereby: one, liquid $\mathrm{HF}$ is confined in the ampoule under its own vapor pressure by sealing the inlet tube of the ampoule; and two, $\mathrm{HF}$ is subsequently transferred to other vessels and to other materials under anhydrous conditions by rupturing the disk of the ampoule. Whereas breakage of the tip or thin wall of the glass ampoule is effected by the mechanical impact from a magnetic hammer of fused wire, the marked increase in the vapor pressure of liquid HF with temperature is used to rupture the disk of the metal ampoule. A disk of $0.025 \mathrm{~mm}$ platinum foil was selected, because disks of this thickness were found to rupture under a pressure near 10 atm in experiments in which nitrogen gas pressures from a cylinder were applied. This disk safely confines $\mathrm{HF}$ in the

*Part of talk entitled "Rupture-disk ampoule for anhydrous addition of HF to a closed bomb" presented by A. R. Glasgow, Jr. at 19th Annual Calorimetry Conference, Nationa Bureau of Standards, October 15, 1964.

${ }^{1}$ Present address: Pesticides Branch, Division of Food Standards and Additives, Food and Drug Administration, Washington, D.C. sealed ampoule at $25^{\circ} \mathrm{C}$ where liquid $\mathrm{HF}$ has a vapor pressure of about 1.4 atm. Rupture of the disk for anhydrous addition of HF to other materials is effected by raising the temperature which causes the internal pressure of $\mathrm{HF}$ in the sealed ampoule to increase to a value exceeding the rupture limit of the disk; at 100 and $150{ }^{\circ} \mathrm{C}$, liquid $\mathrm{HF}$ has a vapor pressure of 10 and 30 atm, respectively.

\section{Construction}

Whereas other types of designs of rupture-disk ampoules based on this principle may be used, the cross-sectional drawing of the ampoule, shown in figure 1, was designed to fit inside a Morey pressure bomb. The ampoule is composed of four parts: a platinum inlet tube, A; a platinum-iridium shell, B; a platinumiridium protective ring, $\mathrm{C}$; and a rupture-disk of platinum foil, D. The ring $C$ is not gold soldered to the shell and serves only as a protective guard for the thin platinum disk, D. The shell B is reused to form a new ampoule by gold soldering a new section of platinum tubing, A, at 4 and a new disk, $\mathrm{D},{ }^{2}$ at 5 as described in the legend to figure 1 .

\footnotetext{
${ }^{2}$ Note: In the sealing of the platinum disk, D, to the shell $\mathrm{B}$ at position 5 , the protective ring $\mathrm{C}$ should not be on the shell portion because of possible alloying through the thin foil D to both parts $\mathrm{B}$ and $\mathrm{C}$. The reason for this precaution is as follows: the gold soldering can form with the thin platinum foil an alloy of 90 percent $\mathrm{Pt}$ and 10 percent $\mathrm{Au}$ which has a melting range of $2950-3125{ }^{\circ} \mathrm{F}$ and therefore cannot be unsoldered by heating from the $\mathrm{Pt}$-Ir alloy (parts B and C) which have a melting point of $3290^{\circ} \mathrm{F}$. In the case of unsoldering the platinum tube $A$ of $0.025 \mathrm{~mm}$ thickness no difficulty was experienced and the unsoldering behaved as expected from the melting points of $\mathrm{Au}\left(1945^{\circ} \mathrm{F}\right), \mathrm{Pt}\left(3200^{\circ} \mathrm{F}\right)$ and the alloy of 90 percent $\mathrm{Pt}-10$ percent $\operatorname{Ir}\left(3290^{\circ} \mathrm{F}\right)$.
} 


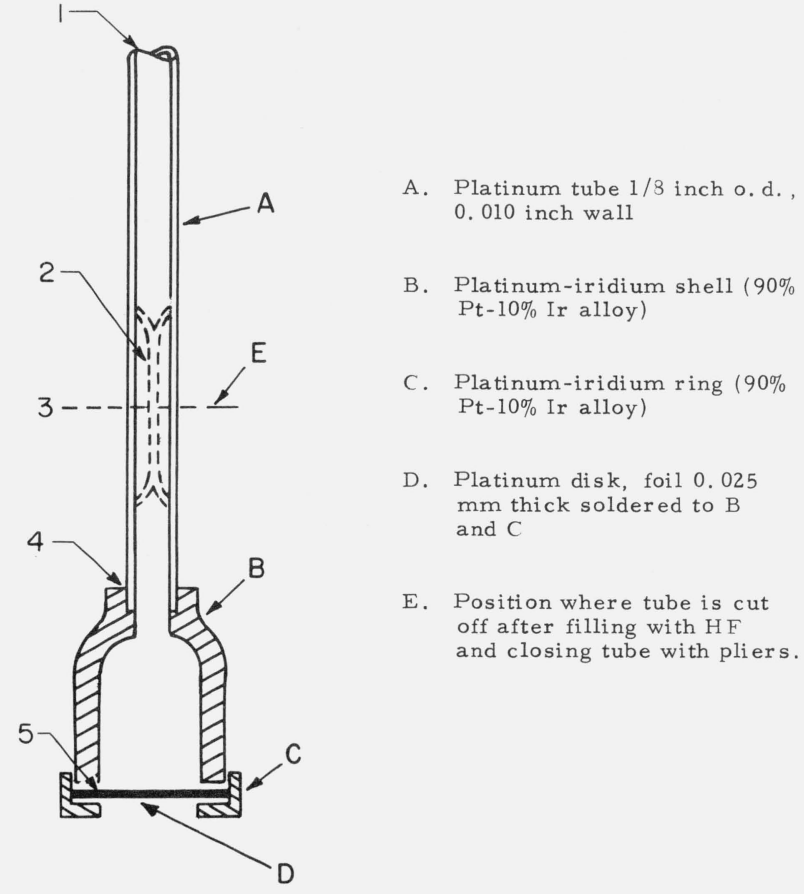

FigURE 1. Rupture-disk ampoule.

\section{Operation}

For filling, the ampoule is attached at its position 1, figure 1, through a union fitting of Monel to a Monel manifold as shown in figure 2. This manifold is joined on one end to a cylinder of $\mathrm{HF}$ gas and on the other end to a high-vacuum system that contains a nickel-Monel trap. Before filling, the ampoule is first evacuated in this manifold to $10^{-6} \mathrm{~mm} \mathrm{Hg}$, tested for leaks with a helium-leak detector, filled with dry air to atmospheric pressure, disjoined from the manifold at the union coupling and weighed. After filling and sealing, the filled ampoule and inlet tube containing the attached union coupling are weighed. From this and the previous weighing, the amount of $\mathrm{HF}$ sealed in the ampoule is determined.

The sequence of operations that is usually performed in glass systems for sealing a volatile substance under its own vapor pressure in a glass break-off-tip ampoule was applied to the metal system of Monel and nickel parts which was used to seal HF under its own vapor pressure in a rupture-disk ampoule of platinum and platinum-iridium parts. These metals were selected because they offer good chemical resistance to $\mathrm{HF}$ whereas glass is attacked. Hydrogen fluoride lended itself well to these operations because of its following properties: boiling point near $19.4{ }^{\circ} \mathrm{C}$; $\mathrm{fp}$ near $-83{ }^{\circ} \mathrm{C}$ where its vapor pressure is about $5 \mathrm{~mm}$ $\mathrm{Hg}$; and a vapor pressure at the temperature $\left(-196^{\circ} \mathrm{C}\right)$ of a liquid-nitrogen bath near $10^{-6} \mathrm{~mm} \mathrm{Hg}$. By the same techniques used with glass systems, HF gas was transferred from a cylinder through the evacuated

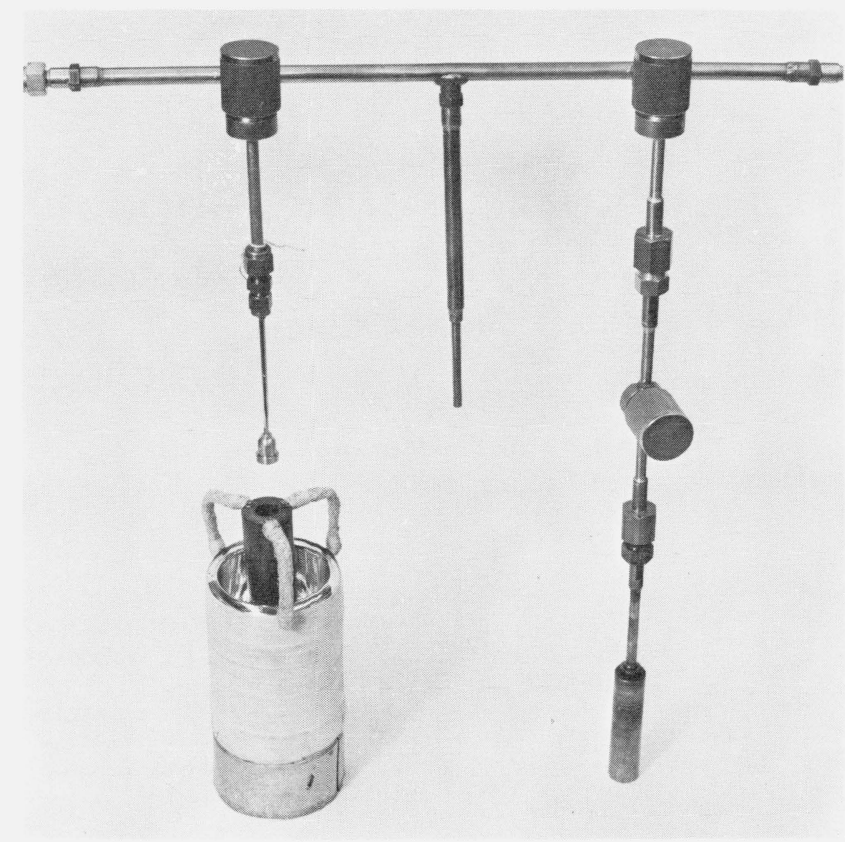

FIGURE 2. Manifold and coolant device used in filling and sealing hydrogen fluoride in an ampoule under its own vapor pressure.

manifold of Monel, condensed in a Monel-nickel trap, alternately frozen and melted in a vacuum to remove dissolved gases, transferred under its own vapor pressure to the rupture-disk ampoule, and then cooled in the ampoule by refrigeration in a liquid-nitrogen bath before sealing the $\mathrm{HF}$ in the ampoule under its own vapor pressure. Since most of these operations do not differ from the conventional practice with glass systems only the final cooling and sealing, which is different, will be described.

For the cooling, the ampoule is placed in the cavity of a solid copper rod that is immersed in a liquidnitrogen bath. This rod is shown in figure 2 in an up-raised position for photographing. A contact medium, such as $\mathrm{CCl}_{4}$, that was added as a liquid and cooled as a solid to $-196{ }^{\circ} \mathrm{C}$, was used to fill the space between the cavity and the ampoule for the purpose of improving the heat transfer between the ampoule, rod, and bath. After cooling the filled ampoule in this manner, the inlet tube $A$ was compressed by pliers with parallel jaws as shown at 2 in figure 1 . This compressed section had been previously annealed to soften the platinum, gold coated on its inner surface, and partially compressed so that a small coil of gold wire fitted just above position 2 in figure 1. After the compression with the pliers, this gold wire is heated to fusion as a final precaution in the sealing. The ampoule after this sealing is allowed to warm to room temperature, tested through the manifold system for leaks, and then disconnected at the union fitting and weighed. After weighing, the ampoule is disjoined from the inlet tube by cutting at position 3 as shown in figure 1 . 


\section{Results}

In a filling of this ampoule with a $0.429 \mathrm{~g}$ amount of $\mathrm{HF}$, the reweighing of the filled ampoule after a weekend was constant to $1 \mathrm{mg}$. This weight was also checked to within $1 \mathrm{mg}$ from the reweighing of the empty ampoule after an experiment in which the ampoule was placed in a bomb and heated to about $125^{\circ} \mathrm{C}$ to release the $\mathrm{HF}$ to the cavity of the closed bomb.

\section{Conclusion}

This technique for the anhydrous addition of a weighed amount of $\mathrm{HF}$ in a rupture-disk ampoule was perfected for use in the development of a new hydrofluorothermal process whereby crystal growth of $\mathrm{BeF}_{2}$ in a platinum-lined bomb under $\mathrm{HF}$ pressure was to be performed by a method analogous to that used in the hydrothermal growth of quartz from $\mathrm{SiO}_{2}$. In the hydrofluorothermal method, $\mathrm{BeF}_{2}$ was to replace $\mathrm{SiO}_{2}$, $\mathrm{HF}$ was to replace $\mathrm{H}_{2} \mathrm{O}$, and $\mathrm{NH}_{4} \mathrm{~F}$ was to be substituted for $\mathrm{NaOH}$ as the flux material. Whereas in the hydrothermal process water is a component and is therefore no problem, the mixing of $\mathrm{HF}, \mathrm{BeF}_{2}$ and $\mathrm{NH}_{4} \mathrm{~F}$ in the bomb under anhydrous conditions was a major problem solved by the rupture-disk ampoule technique.
Although the ampoule discussed was specifically designed for use in the above process, this technique is described because of its general utility in other applications where a weighed amount of $\mathrm{HF}$ is to be mixed with other materials or added to vessels under anhydrous conditions. The filled and sealed ampoule allows HF to be added at room temperature to vessels under anhydrous conditions along with nonvolatile solids; and after closure of the vessel to be mixed with the contents of the closed vessel.

In cases where heating the HF-filled and sealed ampoule is not desirable, the disk may be punctured by mechanical impact by techniques such as fusing a wire to release a weight for puncturing the disk.

This work was part of the research into methods for the preparation of high-purity, well-characterized, crystalline $\mathrm{BeF}_{2}$ which was supported by the Advanced Research Projects Agency in the Light-Element Program at the National Bureau of Standards.

(Paper 70A2-389) 